\title{
Evolution of Distribution Channels in Entertainment Industry
}

\author{
Hongyu Duan
}

\author{
Finance, Fisher College of Business, The Ohio State University, OH, Columbus, 43201, United States
}

Email: duan.268@osu.edu

\begin{abstract}
The entertainment industry's distribution channels have now progressed through four stages. People spread through word of mouth in the first stage, books and magazines in the second stage, television in the third stage, and now, in the fourth stage, various mobile phone applications. The ability to receive news quickly and easily has resulted in great convenience, and everyone's life has become rich and colorful. Furthermore, the status of message producers and receivers is always changing. From the beginning of the inequality to the present, receivers have the ability to delete videos they do not like. In the entertainment industry, audiences hold a commanding position. People will consume for their favorite shows or celebrities, and they will delete content they don't like right away. As a result, the relationship between the message maker and the audience has become very important, because the message maker requires more feedback messages to make adjustments to different projects to meet the needs of people today, rather than arbitrarily promoting entertainment based on their own ideas.
\end{abstract}

Keywords: Distribution channel, value, industry development

\section{INTORDUCTION TO INFORMATION DISTRIBUTION IN ENTERTAINMENT INDUSTRY}

Receiving the latest news is an important part of most people's lives. Nowadays, various network platforms in the entertainment industry provide convenience for everyone. People receive news from radio and television, but as more advanced technologies are produced, then they are beginning to get their latest news from different social media. Iqiyi, Youku, Tik Tok, Tencent, Little Red Book (a platform for young people's lifestyle in China), Weibo and other platforms are becoming people's indispensable entertainment source. These entertainment channels have already penetrated into our lives and watching these entertainment videos on a daily basis has been viewed as an integral part of us. Even if they live in a remote location, they still can keep up with the current events and national affairs. We can watch the most popular variety shows, TV dramas and movies, which can be made clearer through technology, on these channels.

\section{IMPACT ON CONSUMERS ON VARIOUS PLATFORMS}

Each platform has provided transcendental enjoyment to the audience and has allowed the majority of consumers enjoy it. Consumers are willing to spend time in the entertainment industry because of the diverse channels it has created, and the market benefits both businesses and consumers. Manufacturers can earn a lot of money and sell more programs to the general public. Consumers are willing to pay to become VIPs and enjoy watching time more efficiently. This method not only meets everyone's needs, but also brings extraordinary business opportunities to the market. Simultaneously, these entertainment channels can inform each software provider about the types of programs that customers prefer and transmit relevant content for them at any time. When people watch a specific type of short video in Little Red Book (a platform for young people's lifestyle in China), a large number of related contents will be launched to consumers' phone screen via background. Consumers will have dependence and purchase psychology as a result of long-term push, which not only attracts a group of loyal consumers, but also the goods all sold. Because of these channels, the market can understand how to attract more consumers to enjoy these products, as well as how to improve the functions of the products to compensate for their shortcomings [1]. At the same time, how will the entertainment industry's economy improve 
quickly, and how can other related industries imitate the economic effects to improve themselves? This is a model that benefits both parties. The entertainment industry has had an economic impact. There are many similar channels bring huge economic effects, but it has not only brought us benefits, but it has also brought disadvantages. For example, young consumers are the most important customers through these channels. They do, however, spend valuable time in their lives [2].

\section{DISTRIBUTION CHANNELS IN DIFFERENT PERIODS}

Communication channels evolve with the times, and each communication channel has own set of characteristics. People initially spread the news through word of mouth. There are no Internet TV, mobile phones, or tablet computers at the time, only black-andwhite TV and radio, which many people couldn't afford. As a result, when one family received the information, he would pass it on to another, and so on. Finally, everyone got the news. Despite the fact that the sentences are as similar as two peas, the main content of the information remains unchanged. This mode of communication is very slow because, if they do not live in the same area, people in the countryside will receive news many days later than those in the city. As a result, the news lag causes inconvenience in many people's lives, and people cannot get the news in time, which has many negative consequences in life and study [3]. However, people's living standards gradually improved later. Many families can afford to purchase a television and a telephone. People can sit at home and catch up on the latest news by watching television. The daily news broadcast will provide real-time coverage of today's national news, while the entertainment channel will provide coverage of the most recent entertainment news. Even if some people cannot afford a television, they can obtain information by phone from relatives and friends. This type of communication speed is much faster than word of mouth at first, and telephone speed is faster than running to other people's homes. People no longer use flip phones after a few years, and touch-screen phones have gained popularity. Weibo is widely available for download. People publish news or upload pictures to share with their friends, and they can even leave comments at the bottom of the content to draw attention on favorite facts, celebrities, variety shows, and so on. Also, they can have attention on friends at the same time for interaction and private messages. This mode of communication is faster than TV and telephone because everyone can check Weibo at any time and from any location to find out what is going on, and someone will send the news to the Weibo. This level of communication speed is incomparable to watching TV or making phone calls. The network makes it easier for people to follow on the latest news. Youku and Iqiyi began to appear, and people were able to upload interesting videos, variety shows, and so on, which were widely broadcast on these platforms. Even if people were traveling abroad, they could watch a variety of interesting TV shows, movies, and variety shows. People's needs are constantly changing, and science and technology are improving all the time. They benefited greatly from this software, and it's more useful than television and cell phones. Everyone pays attention to their favorite video numbers, watches their most recent videos, learns new things, and has fun.

\section{SALIENT FEATURES OF DISTRIBUTION CHANNELS}

People have all kinds of communication channels, advanced science and technology, and they can get the most up-to-date news in the shortest amount of time. It has made significant progress in comparison to the past. The distinguishing feature is that it allows people to keep up with current events, improve according to new news at the fastest speed, and greatly improve their lives. Furthermore, people use this method to send messages to others in different locations to ensure that the information they receive is accurate and reliable, and that they can respond to the surrounding environment at any time [4].

\section{EVOLUTION OF DISTRIBUTION CHANNELS}

When people first began to spread information, communication was equal because the number of communicators and receivers was equality, and power was balanced. So, everyone has the same rights and obligations to listen to the news and then spread it. At that time, everyone will listen to every message, ensure that they are keeping up with society's pace, and then make changes based on the content. After that, books, magazines, and any other paper-based content can be saved. People start getting the latest news by purchasing newspapers and magazines. This type of communication speed saves a lot of unnecessary time, and people no longer need to run around and tell each other [5]. This type of communication channel, on the other hand, converts the content passed down from mouth to mouth into print. However, not everything said by everyone can be printed. The press chooses valuable content to print into books that people can read. There is an inequality relationship here because some worthless content is naturally abandoned. Because few contents had been chosen from when these books first became popular, the rights of the information producer were greater than those of the receiver. They can send whatever they want to spread, and people can only choose from a limited set of contents. This channel of distribution elevates the status of information producers. Even if people don't understand the content or dislike a portion of it, they must try to comprehend it because 
there is no other option. Everyone's life has become more diverse since then and visions have been influenced by television and telephones. They no longer need to buy newspapers, magazines, or books to stay up to date on the latest news. On the contrary, people get the most recent news by simply sitting at home. At this time, these messages are strictly controlled, the status of the message maker is still higher than that of the receiver at this time. There are strict rules governing which messages can and cannot be broadcast. Every day, news that is beneficial to society will be broadcasted in various TV stations, and people can follow this standard. It is especially important that many TV shows, movies, and variety shows can be broadcasted on television, providing people with a strong sense of picture. At the same time, message creators can profit from a variety of platforms. The recipients, according to the broadcast programs, can only obtain physical and mental pleasure, not benefits. People could also communicate and discuss their ideas over the phone at the time. This significantly alleviates the inconvenience of geographical location. People can talk about the latest entertainment news and share their emotions with friends who live in other countries. At the same time, people have the option of saying what they want to say or hiding what they don't want to share. Receivers have the right to express themselves through Weibo and short-hand videos as the times progress. They can use these platforms to share their life trends, create interesting short videos to share with family and friends, attract fans, and even open relevant live broadcasts. As a result, the status of message recipients far outweighs that of message makers, because they can choose to watch their favorite content or delete videos they dislike. Furthermore, people can create value for themselves on various platforms, absorb fans, and generate higher income. But message makers need more people, and they are no longer dominant because an increasing number of entertainment messages are emerging and forming a different number of receivers. If these creators want to gain more fans and benefits, they must align their content with the current public's love, forming an interaction relationship. Thus, in order for message makers to gain benefits, the receiver must accept them and consume money in it.

\section{IMPACT OF DIFFERENT DISTRIBUTION CHANNELS}

The various stages of distribution have had a significant impact on the entertainment industry. The prototype of the entertainment industry, such as a scene with an entertainment function, was created by word of mouth, but this industry has yet to form. People perform the functions of expressing, communicating, and transmitting information here. Its most significant impact is that it allows everyone to share and communicate very effectively over short distances, and this type of sharing and communication can result in factual feedback. It lays the bedrock for the occurrence of entertainment scenes. This industry will emerge when everyone has the ability to receive and generate information. For example, information and communication are only meaningful when more than one person can generate and receive it. Only one person could express and spread ideas in the stone age, but everyone else could not hear, see, or touch, there would be no communication, and there would be no industry. The foundation of the entertainment industry is books and magazines. They make information more visible, disseminate it more widely, and keep it for a longer period of time. Allowing people to become acquainted with it, to see entertainment news on a daily basis, and to provide consumers with relaxation. Only when information is disseminated frequently and widely, it can be considered as an industry. The entertainment industry has emerged as a result of the thousands of books and magazines that write these stories and murals that record them. Every week, some magazines publish interviews and photos of various celebrities. When people want to learn more about entertainment news, they will buy each magazine and read the articles. Later, telephones and televisions became necessities for every family to keep up with current events and news. It broadcasted the most recent entertainment news to the general public and was no longer as the static images found in books and magazines, but it had become more vibrant and appealing to consumers. At the same time, these celebrities and television networks profit from them. Because there are more types of telephone and television that can meet more business needs, the emergence of advertising has produced more business values, allowing these values to be improved. People used to have to pay for the production costs of books and magazines, but now they have to pay for TV subscriptions. The appearance of some advertisements is one of them. Because it encourages cross-border consumption. When people see advertisements, they may purchase fitness equipment, gifts, or drugs, increasing consumption opportunities and expanding the entertainment industry. There are now more interesting apps available, such as Weibo, Little Red Book (a platform for young people's lifestyle in China), and so on. They broaden people's visions and create more short videos rather than monotonous shows or TV programs. The industry has become rich and colorful as a result of this change. Everyone has the potential to become the center of information creation. This entertainment industry is no longer in the hands of a single individual but has evolved into a platform for attracting more people to participate. More value is created when a large industry develops and implements a business model. Therefore, the entertainment industry has grown more diverse and decentralized. There is no longer a center; instead, everyone is the center. It is more diverse than the previous stage. Because of the 
two-way dissemination of information, we took the reporter as the center and designated TV stations to spread outside at the time. The emergence of these various platforms now allows for two-way information dissemination, and anyone can distribute information and respond. When we open the Little Red Book (a platform for young people's lifestyle in China), we will notice that the users we followed have added many new contents, such as beauty makeup, funny jokes, life skills, and so on. After reading it, we can also leave comments on the part we like and the content we'd like to see in the next period, and the bloggers will update them in real time. We can also remove the content we don't want to see and search for the short video we want to watch.

\section{LONG-TERM BENEFITS FOR CONSUMERS}

Distribution channels not only improve the entertainment industry's bottom line, but also make content more specific and vivid. Many previous messages cannot be saved because they are insufficiently rich. People can only receive information; they can't express themselves, and there's no two-way communication. Therefore, many programs cannot be effectively improved, and producers behind the scenes are unaware of consumer needs. In order to attract the attention of more consumers in the future, we must improve its feedback channels. People can make appropriate suggestions based on their own ideas to diversify the entertainment industry and improve distribution channels. People can save it in the first stage, which is represented by word of mouth. It is no longer necessary to spend time and energy on oral information dissemination because this may result in inaccurate information dissemination. In the second stage, which is represented by books, newspapers, and magazines, the paper contents are converted to electronic versions so that they can be kept for a longer period of time and the words within do not fade. People will have a more intuitive visual experience in the third stage, which is represented by computers and television. In the future, whenever and wherever people want to buy things on TV, they may approach remote presence by transmitting electrical signals into taste and smell. Consumers can get a firsthand look at the products they want to buy and choose more if they enjoy the process. This has also resulted in increased benefits for the entertainment industry. The number of consumers has grown, and they are now willing to pay for sounds and images. They don't have to eat or broadcast after they've been transformed into taste and smell. We will only need to copy the signal in the future to be able to eat anywhere. Furthermore, the social form has been altered, and people can be presented remotely. If people are in Shanghai or Beijing, they can see and experience what they're doing to determine whether it's meaningful or meaningless. Normal people, as represented by Weibo and Tik Tok are more active than celebrities in the fourth stage. These people, for example, make a lot of interesting short videos. They got a large number of fans and have earned the title of Internet Celebrity. Even though consumers are a 70-year-old man, they will have the opportunity to become well-known in the network. Because there are numerous similar videos available on a variety of platforms. What needs to be kept in mind is that the development of distribution channels takes a significant amount of time to observe and study. Being too impatient will destroy the entire industrial chain and cause people to suffer losses.

\section{CONCLUSION}

From the perspective, this evolutionary process has been extremely successful. People use distribution channels to raise their standard of living, improve their quality of life, and generate more wealth for themselves and society. Furthermore, methods such as remote shopping are being expanded so that people can enjoy different benefits and live an interesting life no matter where they are. Evolutionary process in distribution channels not only has the entertainment industry been greatly impacted, but also have a variety of other industries. People enjoy the same advantages and convenient services.

\section{REFERENCES}

[1] Antikainen, H., Kangas, S., \& Vainikainen, S. (2004). Three views on mobile cross media entertainment. VTT Technical Research Centre of Finland. VTT Information Technology. Research Report No. TTE4-200417 http://www.vtt.fi/inf/julkaisut/muut/2004/cross media_entertainment.pdf

[2] Beal, C., Beck, J., Westbrook, D., Atkin, M., \& Cohen, P. (2002). Intelligent modeling of the user in interactive entertainment. In AAAI Stanford Spring Symposium, Stanford CA.

[3] C. C. Wong and P. L. Hiew, "Mobile entertainment: review and redefine," International Conference on Mobile Business (ICMB'05), 2005, pp. 187-192, doi: 10.1109/ICMB.2005.64.

[4] Oliver, M. B., \& Bartsch, A. (2011). Appreciation of entertainment. Journal of Media Psychology.

[5] Pihlström, Minna, and Gregory J. Brush. "Comparing the Perceived Value of Information and Entertainment Mobile Services.” Psychology and Marketing, vol. 25, no. 8, 2008, pp. 732-755., https://doi.org/10.1002/mar.20236. 